\title{
Application of the vegetation index to urban planning
}

\author{
Nikolay Bondarenko*, Tatyana Lyubimova, and Yulya Reshetnikova \\ Stavropolskaya St., 149, 350040 Krasnodar, Russia
}

\begin{abstract}
This article contains data on the change in the NDVI (Normalized Difference Vegetation Index) over a 10 year period from 2009 to 2019 obtained for identification of terrestrial vegetation using satellite images of high spatial resolution in the territory of the Novorossiysk agglomeration. The degree of degradation of the vegetation within the urban agglomeration and surrounding areas has shown the complexity of the overall structure due to finer gradations. Areas with oppressed vegetation connected both with the state of vegetation in this season of the year, and with the increase in the proportion of artificial objects were identified. Some special features of revegetation with due consideration of climate pattern are provided. The vegetation index data can serve as a source of information on the intensity of tree and shrub vegetation for making correct decisions regarding the development of modern urban environment.
\end{abstract}

\section{Introduction}

Green spaces are one of the main factors in creating conditions for a quality and comfortable urban environment and arranging recreational areas; they are a part of territorial planning and development of populated areas. The problem of preserving and developing green areas (parks, squares, protected areas) as well as researching possible revegetation of disturbed lands is one of the most important issues for Novorossiysk, which is both an industrial port city and a resort.

Vegetation assessment through calculation of vegetation indices is widely used in various fields [1 - 4]. Such studies have been conducted for the territory of the Krasnodar Krai: assessment of the state of agricultural crops, monitoring the dynamics of estuary vegetation in the Kuban River Delta, etc. [5, 6]. The purpose of this study is to determine and describe the state of vegetation of the Novorossiysk agglomeration and adjacent areas using the vegetation index obtained from space images.

\footnotetext{
${ }^{*}$ Corresponding author: nik_bond@mail.ru
} 


\section{Materials and methods}

The urban fabric of Novorossiysk is located in the valley of the Cemes River. A commercial port, developed marl deposits, 5 cement plants, oil terminals, a car repair plant, and a passenger railway station are located in the eastern part of the city; the western part is mostly a residential area where most of the population is concentrated (Fig. 1).

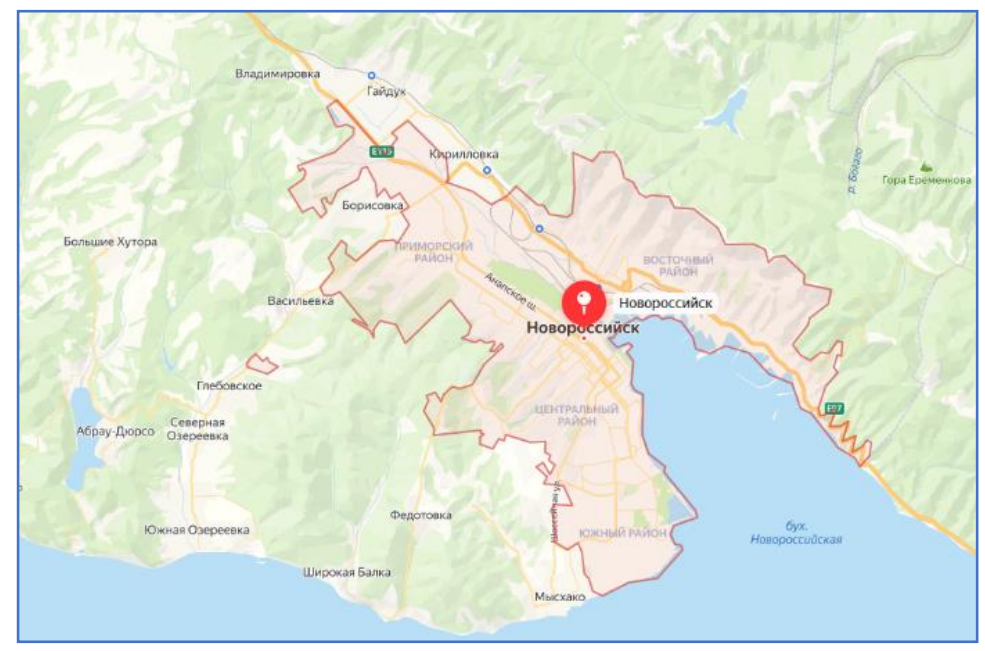

Fig. 1. Location of the study object.

Geographical location as well as geological and geomorphological features of the southern slope of the North-Western Caucasus determine the nature of the vegetation cover of the studied territory [7]. The slopes composed of marly rocks are considered dry; they are covered with vegetation communities dominated by the Jerusalem thorn. Relict mountain steppes, steeped meadows with elements of upland xerophytic vegetation are abundant at the watershed areas. Typical plants here are junipers. Mainly oak and oak and grab forests grow at the highlands near the watershed areas. Beech and chestnut forests prevail on the eastern exposure slopes. Undergrowth is diverse; it is composed of European bladdernut, cornel and privet. Mountain steppe and mountain meadow vegetation is developed at the altitudes above $400 \mathrm{~m}$, where there is no forest vegetation [8]. In general, the territory is characterized by semistructured soils with low humus content.

In accordance with the provisions of SP 42.13330.2012 [9], Novorossiysk must have at least $10 \mathrm{~m}^{2}$ of public green spaces per 1 resident, i.e. at least 315 hectares of green spaces. Within the city, there are such designated natural territories as "Sujuk Lagoon" natural monument as well as "Tsemes Grove" and "Pioneer Grove" forest parks, which can be considered as phytometers of the city territory.

Methodically, the work was carried out by calculating the NDVI, which reflects the amount of green phytomass [10]. Interpretation of the obtained values was carried out based on the accepted discrete NDVI scale, where all values are located in the range from 1 (oppressed) to 1 (natural background). It is established that this index takes the highest values for the territories with abundant vegetation.

NDVI is calculated using a formula in which the numerator is the difference between the near infrared reflectance (NIR) and the red reflectance (RED), and the denominator is their sum. 
Studies carried out with the application of the vegetation index [11] show that spectral range of values for vegetation is much higher than that for other objects of the Earth's surface. This is primarily because the value of the index depends on the species diversity of vegetation; it is influenced by seasonality, as well as the exposure of the slope and other factors.

As shown in Table 1, the near infrared and red reflectance specific features allow for the recording of stable NDVI values for natural objects of different origin.

Table 1. NDVI index values for different object types [12].

\begin{tabular}{|c|c|c|c|}
\hline Object Type & $\begin{array}{c}\text { Reflection in } \\
\text { red region } \\
\text { (RED) }\end{array}$ & $\begin{array}{c}\text { Reflection in } \\
\text { infrared region } \\
\text { (NIR) }\end{array}$ & $\begin{array}{c}\text { NDVI } \\
\text { Value }\end{array}$ \\
\hline Dense vegetation & 0,10 & 0,50 & 0,70 \\
\hline Sparse vegetation & 0,10 & 0,30 & 0,50 \\
\hline Exposed soil & 0,25 & 0,30 & 0,025 \\
\hline Clouds & 0,25 & 0,25 & 0 \\
\hline Snow and ice & 0,375 & 0,35 & $-0,05$ \\
\hline Water & 0,02 & 0,01 & $-0,25$ \\
\hline
\end{tabular}

Remote sensing data from the LAND VIEWER platform were used as initial. Data from the summer seasons of 2009 (8.07.2009) and 2019 (12.07.2019) were taken for accurate comparison and accounting of seasonal climatic indices.

\section{Results and discussion}

Based on the results of processing the images using the NDVI values, their spatial distribution was obtained. It is shown in Figure 2 and reflects the actual surface types of the studied territory. Having done the NDVI calculations using the formula (1) we obtained the following values:

$$
\begin{aligned}
& \text { for } 2009=\frac{\mathbf{B}_{81,40}-\mathbf{B}_{72,29}}{\mathbf{B}_{81,40}+\mathbf{B}_{72,29}}=-0,39 \text {; }
\end{aligned}
$$

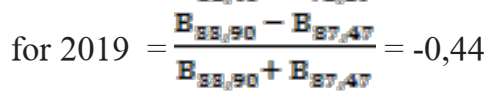

Since the established decrease in the vegetation index is associated primarily with an increase in the proportion of sparse vegetation due to specific features of weather conditions of the summer seasons of 2009 and 2019, as well as with an increase in areas where artificial objects are located, the territory was further clustered by object types (Fig. 3). Numerical values of the NDVI for such clusters are presented in Table 2.

The obtained results show that over the past 10 years, the overall ratio of the different surface types identified by the NDVI values has changed significantly. The total technological load on the territory has increased. In the western part, the proportion of vegetation in valleys and vineyards has increased, while in the inner-city areas grassland has replaced the juniper open woods. The area of Novoroscement JSC industrial in the eastern part has transformed due to the ratio of territories with sparse vegetation and exposed soil. 

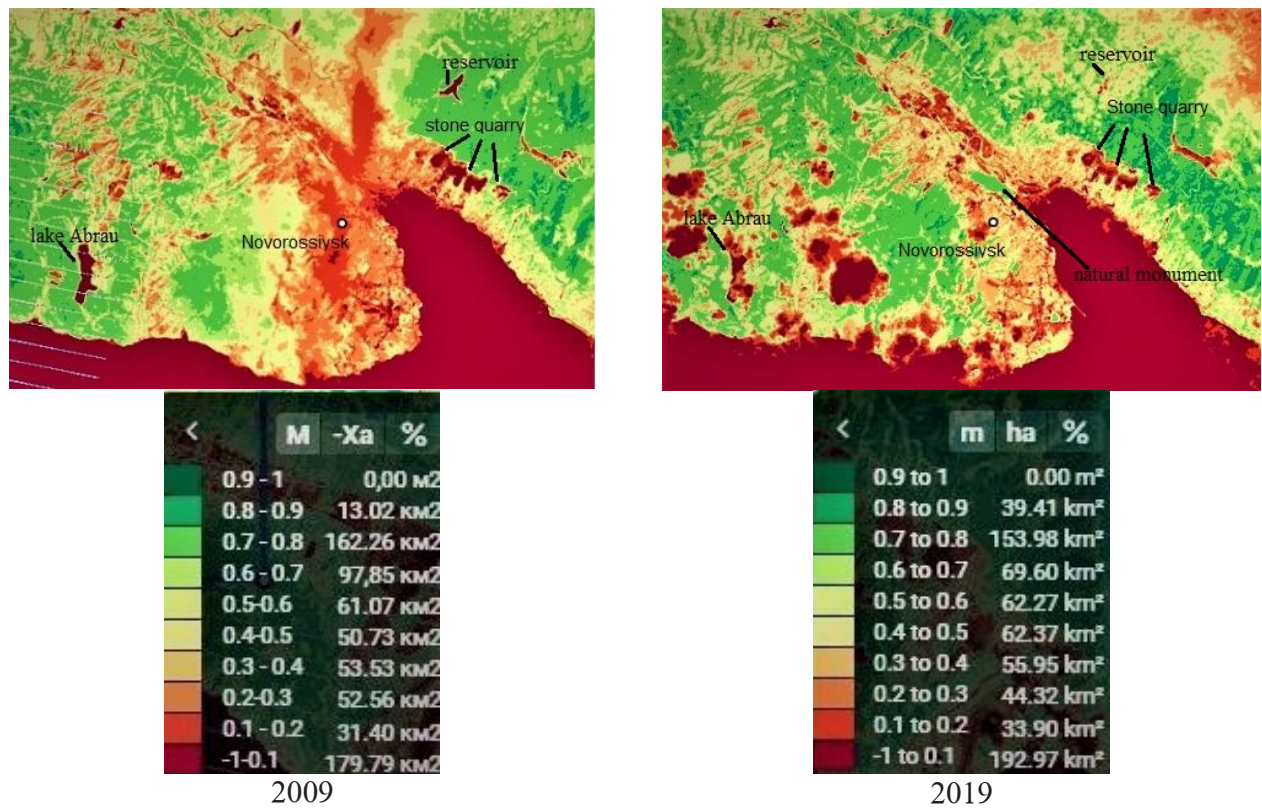

Conventions: changes in NDVI values

Water or low NDVI level

Mineral ground or moderately oppressed vegetation

Vegetation or high NDVI level

Fig. 2. Territory of the Novorossiysk agglomeration using the NDVI index.

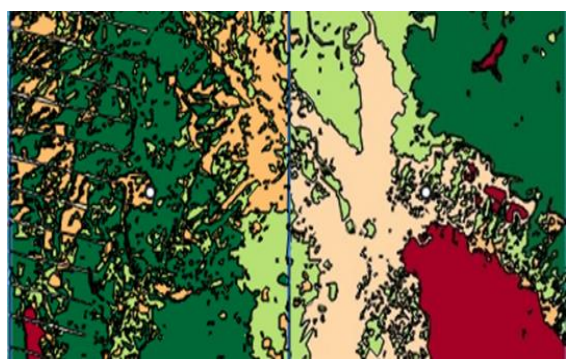

2009

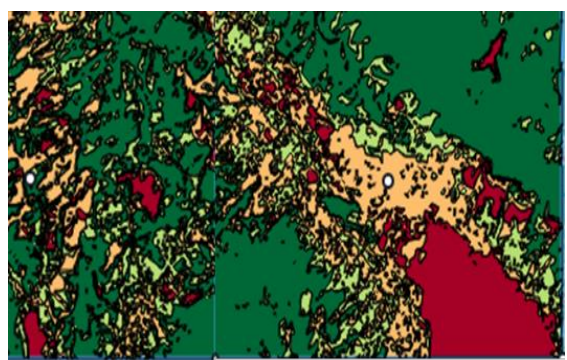

2019

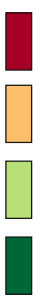

Conventions: changing NDVI index values

Water (artificial materials)

Exposed soil (mineral ground)

Sparse vegetation

Dense vegetation

Fig. 3. Clustering of Novorossiysk and surrounding areas by object type.

The data received, on the one hand, reflect the results of the measures taken in the city to preserve green spaces (over the past period, fruit trees and shrubs have been planted at the curtilages and common grounds, green lawns and flower beds have been laid out), and 
on the other hand, they demonstrate the complexity of the cluster structure due to the development of the general infrastructure of the city.

Table 2. Values of NDVI in the territory of the Novorossiysk agglomeration.

\begin{tabular}{|c|c|c|}
\hline \multirow{2}{*}{ Object Type } & \multicolumn{2}{|c|}{ NDVI value, $\mathbf{k m}^{\mathbf{2}}$} \\
\cline { 2 - 3 } & $\mathbf{2 0 0 9}$ & $\mathbf{2 0 1 9}$ \\
\hline Dense vegetation & 91,18 & 60,68 \\
\hline Sparse vegetation & 27,31 & 42,69 \\
\hline Exposed soil & 19,52 & 33,72 \\
\hline Water & 21,34 & 22,05 \\
\hline Artificial objects & 1,38 & 4,61 \\
\hline
\end{tabular}

\section{Conclusions}

1. The work done has shown the transformation of the vegetation of the urban landscape and the surrounding areas. The use of the NDVI makes it possible to identify areas with oppressed vegetation and clearly identify urban areas, quarries, dumps and areas of natural overgrowth.

2. The human impact on the vegetation cover within the Novorossiysk urban agglomeration is manifested both as its complete destruction with later creation of cultivated cenoses and adaptation of natural vegetation to urban environment.

3. Greenspace expansion in Novorossiysk can be difficult as the slope type of terrain is characterized by relatively low forest cover percent. To restore vegetation cover, it is necessary to take into account the climate pattern: we recommend planting species that are not care-demanding (do not need watering) as well as full-storied planting: trees, shrubs, lawn.

4. Thus, urban landscaping activities can be based on data on the NDVI as a source of information on the intensity of tree and shrub vegetation and its spatial distribution, allowing development of planning and landscaping strategies.

\section{References}

1. A. S. Cherepanov, Geomatics, 2, 98 (2011)

2. D. Doley, P. Audet, D. R. Mulligan, Agriculture, Ecosystems and Environment, 163, 85 (2012)

3. B. Gizachew, S. Solberg, E. Næsset, et al., Carbon Balance Manage, 11, 13 (2016)

4. N. A. Sokolova, I. N. Gossen, D. A. Sokolov, Ecology and industry of Russia, 24(1), 62 (2020)

5. N. A. Bondarenko, T. V. Lyubimova, Y. M. Reshetnikova, IOP Conf. Series: Earth and Environmental Science: Int. Scientific and Practical Conf. on Ensuring Sustainable Development in the Context of Agriculture, Green Energy, Ecology and Earth Science, 723(3) (2021)

6. A.V. Pogorelov, K.V. Kuznetsov, A. S. Stablovsky, Geoinformational support for spatial development of the Perm Krai: Perm State National Research University collection of research papers, 4 (2011) 
7. T. V. Lyubimova, N. A. Bondarenko, A. V. Pogorelov, Polythematic online scientific j. of Kuban State Agrarian University: scientific j. of KubSAU, 121(07), 121 (2016)

8. Ya. P., Didukh, S. A. Litvinskaya, V. V. Novosad, Botanical j., 75(4), 495 (1990)

9. SP 42.13330.2012 Urban development, Urban and rural planning and development

10. R. E. Crippen, Remote Sensing of Environment, 34, 71 (1990)

11. A. S. Cherepanov, E. G. Druzhinina, Geomatics, 3, 28 (2009)

12. T. A. Adamovich, G. Ya., Kantor, T. Ya., Ashikhmina, V. P. Savinykh, Theoretical and applied ecology, 1, 18 (2018) 